\title{
Self-esteem- its influence and structural changes in the lives of tribal students of Kannur district, Kerala
}

\author{
Prajina.P.V ${ }^{1}$, Dr.J.Godwin Premsingh ${ }^{2}$ \\ 1 Research scholar, Department of Social work, Bishop Heber College,Bharathidasanuni, India \\ 2 Research Guide, Department of Social work, Bishop Heber College, Bharathidasanuni, India
}

\begin{abstract}
Researchers are in tremendous controversy regarding self-esteem and its correlates. Self-esteem is an important pillar of psychological well-being. Most of the studies agree with this judgment. Adolescence is a period in which people try to be independent and they start to evaluate themselves self-esteem is a contributing factor for positive behavior. Tribal is the natural inhabitant of the forest or hilly area. They hesitate to keep good relationship with the outside community. But the present needs of life make them to come out side. But there they are supposed to face a lot of challenges. These people must be mentally competent. In this article the researcher tries to find out the level of self-esteem among the tribal students and the relationship between the socio-demographic characters and the self-esteem with special reference to the Kannur district of Kerala.
\end{abstract}

Keyword: Adolescents,self-esteem, tribes,

\section{Introduction}

Now a day Self-esteem is a widely used term in social science to reveal a person's own worth. Selfesteem is considered to be one of the most important pillars of healthy personality development (Ruth YaseminErol and Ulrich Orth,2011).It is an evaluation as well as a perception toward the self or the positive and negative evaluations of the identity. Self-esteem is also known as the evaluative dimension of the self that includes feelings of worthiness, prides and discouragement (E. R. Smith/D. M. Mackie, 2007). Self-esteem is defined as the experience of being competent to cope with the basic challenges of life and being worthy of happiness (Nathaniel Branden , 1969). The author also reveals that self-esteem is the totality of self-confidence and self-respect. Many theories have suggested that self-esteem is a basic element of human needs or motivation. It has been included in the hierarchy of needs put forwarded by American psychologist Abraham Maslow. According to him, until and unless we fulfill the self-esteem it is difficult to reach inself-actualization. A person's self-esteem is a significantelement affecting their mode of life and well-being. With good selfesteem, people do constructive things for themselves and with poor self-esteem, avoid doing such things.

Adolescence is popularly known as a period of stress and storm during which a person learns to cope effectively with the society. It is a critical time for people to improve their social and emotional skills. They try to find out a meaning to their own life and keeping immense relationship with peers. The present generation seems to be emotionally very troubled than the last, more depressed and nervous, (ShobhaNandwana and Kushagra Joshi, 2010). The situation among the tribe is nothing different. "The tribal people being the original inhabitants of India constitute a significant part of the vast nation. They have been dwelling in the forests surrounded by hills for a long period. Their social structure, culture and language are quite different from the general people of India" (Thakur and Thakur, 1994). In Kerala while comparing with the mainstream the psycho social well-being of tribe is poor. Studies show that the achievement motivation among tribes is very low. They don't have sufficient interest in learning. It keeps them away from schools ( JahnabeeLahkarBoruah ,2012) . The self- esteem is an important contributing factor to then adolescent mental health. In this paper the researcher tries to find out the self -esteem among the tribal students of Kannur district Kerala.

\section{Literature Review}

1 Brent Donnellan et al. (2005) reveals that there is a strong relationship exist between low self-esteem and behavior problems - such as antisocial behavior, delinquency and aggression.

2 Roy F. Baumeister, et.al (2003) shows that self-esteem does not contribute more to the academic performance, but high self -esteem may be the result of good academic performance. People those having high self-esteem function effectively in their profession.

3 Jeannel.tsai, et.alreveals that cultural orientation is an important predictor of self-esteem among Chinees American and those who follow American culture shows high self-esteem than the other. His study also explains there is significant difference in self-esteem with respect to the gender.

4 Ruhul Amin Ahmed,(2012)explains that there is significant difference in the self- concept between tribal and nontribal students. 
5 Ulrich Orth, et.al(2010) shows in their study, self-esteem rises during young and middle adulthood, touches a peak at $60 \mathrm{~s}$, and decrease in old age. This study also shows women have lower self-esteem than the men in young adulthood, but the curves of the two sexes congregated in old age.

\section{Objectives Of The Study}

- To understand the socio-demographic profile of the respondents

- To assess the self-esteem level among the respondents

- To find out the influence of socio-demographic variable $\mathrm{s}$ to the self-esteem.

\section{Hypothesis}

- There is no significant difference between male and female with respect to the self- esteem.

- There is no significant difference in the self- esteem with respect to the age of the respondents

- There is no significant difference in the self-esteem level with respect to the birth order of the respondents.

- There is no significant difference in the self-esteem level with respect to the father's job

- There is no significant difference in the self-esteem level with respect to the mother's job

\section{Methodology}

The researcher conducted a descriptive study among the tribal students of a Government school in Kannur district, Kerala. 15 girls and 15 boys were randomly collected from that particular high school. The researcher used Rosenberg's Self-Esteem Scale (1965) to understand the level of self-esteem and a selfstructured questionnaire to collect the socio-demographic information about the respondents.

\section{Analysis and Findings}

In this study $40 \%$ of the respondents are from the age group of $12-13$ and $60 \%$ of the respondents are from 14-15. $40 \%$ of the respondents are studying in VIII standard, 50\% are studying in IX standard and 10\% of the respondents are in X standard. Among the respondents $96.7 \%$ are living in rural area and 3.35 are coming from the urban area.The literatures also show that most of the tribal people are inhabited in rural or hilly areas.The researcher also considered the occupation of parents. Fathers of $10 \%$ respondents were working in private sector, $70 \%$ were daily wages. The pathetic thing is $20 \%$ of the respondents have no father. The result is not different in case of mothers; $20 \%$ of them are working in private sector and majority of them are daily wages. With respect to the reviews the researcher also took birth order as a variable. Among the respondents 46.7\% are first born, 13.35 are middle born and the remaining percentage are first born.

Level of self-esteem among the respondents

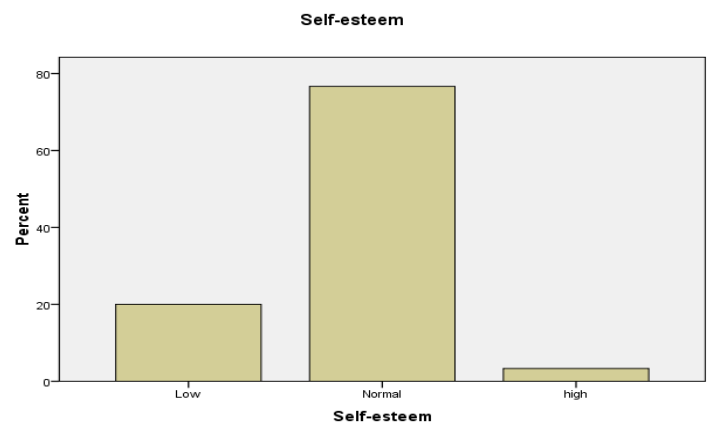

Figure 1

"Fig" 1 shows the level of self-esteem among the respondents. 20\% of the respondents show low self- esteem, $3.3 \%$ of the respondents show high self-esteem but the majority of the respondents $(76.7 \%)$ show normal selfesteem level.

Table 1

Difference in the self- esteem level with respect to the sex of the respondents

\begin{tabular}{|l|l|l|l|l|l|}
\hline Sex & Size & Mean & Std.Deviation & t value & P value \\
\hline Male & 15 & 1.67 & .488 & & \\
Female & 15 & 2.00 & .378 & 2.092 & 0.04 \\
\hline
\end{tabular}


Since the $\mathrm{P}$ value lies between $0.01-0.05$ the null hypothesis is rejected at $5 \%$ level significance. Hence conclude that there is significant relationship between sex and level of self-esteem. The mean value also shows that, in this study the self-esteem among tribal girls are higher than that of tribal boys.

Table 2

Difference in the level of the self-esteem with respect to the age of the respondents

F test

\begin{tabular}{|l|l|l|l|l|l|}
\hline Age & Size & Mean & Std.Deviation & F value & P value \\
\hline $12-13$ & 12 & 1.92 & .515 & 0.645 & 0.429 \\
& & & & & \\
$14-15$ & 18 & 1.78 & .428 & & \\
\hline
\end{tabular}

The above table shows that the $\mathrm{P}$ value is greater than 0.05 , hence the null hypothesis is accepted at $5 \%$ level significance. It shows there is no significant difference in the self-esteem of tribal adolescents with respect to their age

Table 3

Difference in the self-esteem level with respect to the birth order

\begin{tabular}{|l|l|l|l|l|}
\hline Birth order & Size & Mean & $\begin{array}{l}\text { Chi-square } \\
\text { value }\end{array}$ & P value \\
\hline First & 14 & 16.96 & & \\
Middle & 4 & 7.12 & 7.71 & 0.21 \\
Last & 12 & 16.58 & & \\
\hline
\end{tabular}

Here the $\mathrm{P}$ value is greater than 0.05 , hence the null hypothesis is accepted at $5 \%$ level significance. It reflects that there is no significant relationship exists between the birth order of the tribal students and their self-esteem.

Table 4

Difference in the self-esteem level with respect to the father's job

f- test

\begin{tabular}{|l|l|l|l|l|l|}
\hline $\begin{array}{l}\text { Father's } \\
\text { job }\end{array}$ & Size & Mean & Std.Deviation & F value & P value \\
\hline Private & 3 & 2.00 & 0.000 & 0.830 & 0.44 \\
Coolie & 21 & 1.76 & 0.436 & & \\
No father & 6 & 2.00 & 0.632 & & \\
\hline
\end{tabular}

The above result shows that the $\mathrm{p}$ value is greater than 0.05 , hence the null hypothesis is accepted at $5 \%$ level significance. It means there is no significant difference occurs in the self-esteem level with respect to the job of father.

Table 5

Difference in self-esteem level with respect to mother's job

Kruskal-Wallis Test

\begin{tabular}{|l|l|l|l|l|}
\hline $\begin{array}{l}\text { Mother's } \\
\text { job }\end{array}$ & Size & Mean & $\begin{array}{l}\text { Chi-square } \\
\text { value }\end{array}$ & P value \\
\hline Private & 6 & 17.58 & & 0.379 \\
Coolie & 24 & 14.98 & .775 & \\
\hline
\end{tabular}


Here the $\mathrm{P}$ value is greater than 0.05 , hence the null hypothesis is accepted at $5 \%$ significance. Conclude that there is no significant difference exists in the self-esteem of the respondents with respect to the mother's job.

\section{Conclusion}

The study shows that in spite of the socio-geographic limitation the tribes keep respect themselves- the majority of the respondents show normal level of self-esteem. Another important result is that the self-esteem among female is greater than male. Also there is no significant difference in the self-esteem level with respect to the age, father's job, mother's job and birth order. Another thing is only one respondent is having high selfesteem, so it is the duty of policy makers and school authority to implement effective intervention programme to promote the psychological well-being.

\section{Journal Papers:}

\section{References}

[1] Ulrich Orth, Kali H. Trzesniewski, Richard W. Robins, Self-esteem development from young adulthood to old age: a cohortsequential longitudinal study, Journal of Personality and Social Psychology, 98(4),2010,645-658

[2] ShobhaNandwana and Kushagra Joshi, Assessment of Emotional Intelligence of Tribal Adolescents of Udaipur: An Exploratory Study, Stud Tribes Tribal, 8(1): 2010,37-40

[3] Brent Donnellan, M., Trzesniewski, K. H., Robins, R. W., Moffitt, T. E., \&Caspi, A. Low self-esteem is related to aggression, antisocial behavior, and delinquency. Psychological Science, 16, 2005 ,328-335.

[4] Roy F. Baumeister, Jennifer D. Campbell, Joachim I. Krueger, and Kathleen D. Vohs, Does high self-esteem cause betterperformance, interpersonal success, happiness, or healthier lifestyles?, Psychological science in the public interest,4(1),2013, $35-38$

[5] Ruhul Amin Ahmed, The self-concept among tribal and non-tribal secondary level students in south Garo Hills, IJCAES Special Issue on Basic, Applied \& Social Sciences, 2,2012, 373-375

[6] Ruth YaseminErol and Ulrich Orth, Self-Esteem Development from Age 14 to 30 Years: A Longitudinal Study, Journal of Personality and Social Psychology, 101(3), 2011, 616-619

[7] FemmieJuffer and Marinus H. van IJzendoorn, Adoptees Do Not Lack Self-Esteem: A Meta-Analysis of Studies on Self-Esteem of Books:

Transracial, International, and Domestic Adoptees, Psychological Bulletin, 133(6), 2007, 1076-1080

[8] S.K.Mangal, General psychology, (Sterling publishers Pvt. Ltd, New Delhi, 2013)

[9] Devendra Thakur and D.N.Thakur, Tribal education, (Deep and Deep Publication Pvt. Ltd, 2009) 